\title{
Kann Nagellack eine chronische Urtikaria verursachen?
}

Nagelkosmetik auf Acrylat- oder Methacrylatbasis kann eine allergische Kontaktdermatitis auslösen. Möglicherweise kann die allergische Reaktion aber auch weiter um sich greifen, wie eine australische Kasuistik vermuten lässt.

Die Dermatologen Dr. Philippa Dickison und Prof. Dr. Saxon Smith von der Universität Sydney berichteten in der Fachzeitschrift "Clinical and Experimental Dermatology“ über den Fall einer 50-jährigen Patientin, die sich mit erythematösen und berührungsempfindlichen Fingern und Händen in der Hautambulanz vorgestellt hat. Ihre Beschwerden bestanden zu diesem Zeitpunkt bereits seit einem halben Jahr. Vornehmlich betroffen war die Region um die Fingernägel, die sich vom Nagelbett abheben. Seit über zwei Jahren trug die Patientin Gelnägel, bis zum Beginn der Beschwerden ohne Probleme (- Abb. 1).

Die Patientin gab an, die Symptome würden sich nach Entfernen des Nagellacks bessern und nach Wiederauftragen verschlimmern. Auf die Nagelkosmetik verzichten wollte sie nicht, weil sie ihre verdickten Naturnägel damit verdecken wollte. Bei der Untersu- chung fielen zudem Effloreszenzen einer Urtikaria auf. Tatsächlich war die Patientin seit 18 Monaten wegen chronischer Urtikaria unbekannter Ursache in Behandlung. Hochdosierte Antihistaminika schlugen nicht an. Auf Hydroxychloroquin folgte Mycophenolat, mit mäßigem Nutzen.

\section{Patchtest bestätigt Verdacht}

Die Verdachtsdiagnose einer allergischen Kontaktdermatitis bestätigte sich im Patchtest: Hier zeigte sich eine positive Reaktion auf Acrylat- und Methacrylatmonomere, die in den von der Patientin aufgetragenen Gelnägeln als Basis verwendet und unter UV-Licht ausgehärtet wurden. Das Phänomen der Kontaktallergie gegen Acrylate und Methacrylate in der Nagelkosmetik ist wohlbekannt. So verwundert es nicht, dass die Patientin acht Wochen nach Absetzen der Gelnägel wieder einen normalen Nagel-

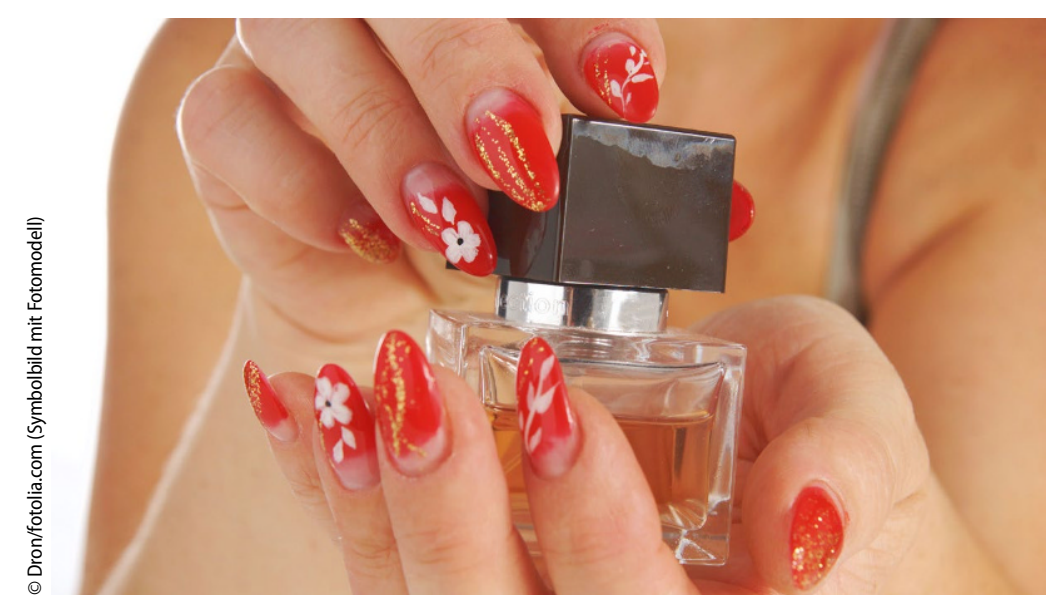

Abb. $1 \Delta$ Die Patientin hatte seit über zwei Jahren Gelnägel getragen, zunächst ohne Beschwerden wuchs aufwies. Auch die Erytheme waren verschwunden.

》) Kontaktallergie gegen Acrylate und Methacrylate ist in der Nagelkosmetik wohlbekannt

Zu diesen erwartbaren Effekten gesellte sich aber noch Überraschendes: Von der chronischen Urtikaria war keine Spur mehr zu entdecken. Die Patientin berichtete, dass sich die Hauterscheinungen nach vier Wochen Gelnagelfreiheit verflüchtigt hatten. Und nun glaubte sie sich auch zu erinnern, dass sich das Hautbild früher jeweils mit dem Auftragen der Gelnägel verschlechtert habe.

"Soweit wir wissen, ist dies der erste Bericht über eine chronische Urtikaria im Gefolge der Applikation acrylatund methacrylathaltiger Gelnägel", schreiben Dickison und Smith [1]. Bewiesen sei der Zusammenhang nicht, der dafür nötige Pricktest hätte die Patientin erneut den Allergenen ausgesetzt. „Der Fall zeigt jedoch, dass ein Beitrag solcher Allergene zu einer chronischen Urtikaria zu erwägen ist, sofern der zeitliche Verlauf mit der möglichen Exposition übereinstimmt."

\footnotetext{
Literatur

1. Dickison P et al (2017) Itching for nail

fashion: chronic urticaria and chronic hand dermatitis secondary to acrylate and methacrylate allergy in gel nail varnish. Clin Exp Dermatol. https://doi.org/10.1111/ced.13252
}

hautnah $2018 \cdot 17: 83$

https://doi.org/10.1007/s12326018-0275-7

(c) Springer-Verlag GmbH Austria, ein Teil von Springer Nature 2018
Quelle: Robert Bublak, SpringerMedizin.de 